\title{
EFFECT OF 80\% WATER SOLUTION OF ANIMAL SLURRY ON CARBON STRUCTURAL S235JRC STEEL AT ROOM TEMPERATURE
}

\author{
Tomasz Lipinski ${ }^{1}$, Dariusz Karpisz ${ }^{2}$ \\ ${ }^{1}$ University of Warmia and Mazury in Olsztyn, Poland; ${ }^{2}$ Cracow University of Technology, Poland \\ tomaszlipinski.tl@gmail.com, dariusz.karpisz@pk.edu.pl
}

\begin{abstract}
Steel in S235JRC grade is a popular unalloyed steel readily used for various structures, including those working in contact with aggressive media. The corrosion of these steels is easy to control. It is usually superficial. One of the more complex corrosive environments is animal slurry. As a result, the corrosive effects of animal slurry are complex and time varying. Slurry is a mixture of dung and urine. The aggressive corrosive constituents in slurry are urea, uric acid, naturally excreted chloride, as well as ammonia or ammonium salts. The purpose of this article is to investigate corrosion resistance in different time $(48,96,144,192,240,288,336,384-$ and 432 hours), using weight loss and profile roughness parameters of structural steel in grade S235JRC in natural $80 \%$ water solution of animal slurry at room temperature $(298 \mathrm{~K})$. Today, corrosion-resistant steels are usually used in aggressive environments. In order to be able to compare the corrosion rate of stainless steel with steel S235JRC, it was decided to carry out the tests based on the methodology of testing corrosion-resistant steels. Corrosion tests show that the tested steel in animal slurry as a corrosive environment is characterized through continuous corrosion process, which measure may be surface roughness. It was found that animal slurry with a room temperature is an aggressive corrosive medium of steel grades S235JRC. A gentle transition between the various stages of corrosion was noted, which is reflected in the surface roughness and corrosion velocity.
\end{abstract}

Keywords: animal slurry, carbon steel, corrosion, corrosion rate, roughness.

\section{Introduction}

S235JRC steel is suitable for cold flanging, cold forming and cold driving. It is a willingly applicated material for construction parts of low and medium strength load, which are not liable to cyclical changes. Construction materials used in industry must meet high requirements. The reason for the high requirements is the need to ensure the safety of people and structures during the operation of technical structures [1-9]. In recent years, when structures are operated in an aggressive environment, corrosion-resistant steels are usually used [10-15]. These steels are expensive and their use in structures operating in an environment with a low degree of aggressiveness is not always justified. An important feature of stainless steels is the tendency to intergranular corrosion difficult to detect by visual inspection. However, it is very dangerous and can lead to unexpected destruction of the material or a significant reduction of its strength properties. Carbon steels hardly suffer from intergranular corrosion [16-19]. Surface corrosion of carbon steel mainly causes thinning of the material, which leads to deterioration of its mechanical properties. This type of corrosion is easier to observe during operation. Of course, the use of unalloyed steels is limited only to less aggressive corrosive environments [20-24].

The properties of the material are influenced by a number of factors. The main ones are the chemical composition and the manufacturing process. Cold-finished steels have higher surface hardness and thus higher mechanical properties in the surface layer. Cold-formed materials thus have a heterogeneous structure across the cross-section. Other factors of heterogeneity are, inter alia, non-metallic inclusions and phase separation. In order to save money, research is often replaced by computer analysis [25-30].

The variety of structures, devices and equipment used in agriculture and agricultural construction is the reason for the contact of the materials used with various corrosive factors among others in animal slurry and its aqueous solution. Products that have leaked into the atmosphere should also be taken into account, such as chloride vapours, $\mathrm{NOx}$ and $\mathrm{SOy}, \mathrm{HzS}$ and others. Penetration corrosion processes of low carbon steel with animal products are very aggressive. Slurry is a mixture of dung and urine, and farmyard manure etc. The corrosive constituents in slurry are first of all: ammonia and its salts, urea, uric acid, naturally excreted chloride [31-36].

Animal slurry is the basic corrosive environment with which structures and machines used in agriculture meet. Bearing in mind the importance of corrosion resistance for operation, these tests determined the corrosion resistance of the S235JRC low-carbon structural steel in an aqueous solution of animal slurry. It was decided to conduct the tests under normal temperature conditions (room temperature). This paper presents the corrosion tests of the cold worked alloy and is an extension of the tests presented in [37-38] for the alloy from the same group not cold worked. 


\section{Materials and methods}

The research was performed on carbon S235JRC (1.0122) steel plate $t=8.00 \mathrm{~mm}$ thickness with chemical composition according to the EN 10277-2:2008 [39]. The real chemical composition of the tested steel is presented in Table 1 .

Table 1

Real chemical composition of S235JRC steel

\begin{tabular}{|c|c|c|c|c|c|c|c|c|}
\hline \multicolumn{7}{|c|}{ Mean chemical compositions, wt.\% } \\
\hline $\mathrm{C}$ & $\mathrm{Si}$ & $\mathrm{Mn}$ & $\mathrm{P}$ & $\mathrm{S}$ & $\mathrm{Cr}$ & $\mathrm{Cu}$ & $\mathrm{Ni}$ & $\mathrm{N}$ \\
\hline 0.16 & 0.2 & 1.28 & 0.03 & 0.03 & 0.1 & 0.10 & 0,09 & 0.009 \\
\hline
\end{tabular}

The specimens from plate $\mathrm{t}=8.00 \mathrm{~mm}$ thickness were cut samples by a mechanical saw to size 40 x $10 \mathrm{~mm}$ (area of $16 \mathrm{~cm}^{2}$ ). Next, the samples were ground on the grinding wheel successively from $\mathrm{R}_{\mathrm{a}}=0.32$ to $\mathrm{R}_{\mathrm{a}}=0.42 \mu \mathrm{m}$ and cleaned by $95 \% \mathrm{C}_{2} \mathrm{H}_{5} \mathrm{OH}$. The samples despite the ferritic-perlitic microstructure were tested in accordance with the standard dedicated for stainless steel ISO 3651-1:1998 [40]. The application of the criteria provided for stainless steel was intended to enable comparative assessment of the corrosion resistance of carbon steel and stainless steel in the future. The corrosive mixture was prepared as an aqueous solution of $80 \%$ animal slurry with the composition shown in Table 2 and Table 3, and 20\% distilled water. Both components were measured by volume. The corrosion resistance of steel was tested by measurement of loss in mass.

Table 2

Mean chemical compositions of animal slurry

\begin{tabular}{|c|c|c|c|c|c|c|}
\hline $\mathbf{P}, \mathrm{mg} \cdot \mathrm{L}^{-1}$ & $\mathbf{K}, \mathbf{m g} \cdot \mathbf{L}^{-1}$ & $\mathrm{Mg}, \mathrm{mg} \cdot \mathrm{L}^{-1}$ & $\mathrm{Ca}, \mathrm{mg} \cdot \mathrm{L}^{-1}$ & $\mathrm{Na}, \mathrm{mg} \cdot \mathbf{L}^{-1}$ & $\mathrm{Zn}, \mathrm{mg} \cdot \mathbf{L}^{-1}$ & $\mathrm{NO}_{3}, \mathrm{mg} \cdot \mathrm{L}^{-1}$ \\
\hline 175 & 158 & 6.4 & 39.2 & 102 & 0.41 & 35 \\
\hline
\end{tabular}

Table 3

Parameters of animal slurry

\begin{tabular}{|c|c|c|c|c|}
\hline $\mathbf{P H}$ & $\mathbf{E C}, \mathbf{~} \mathbf{~ S} \cdot \mathbf{c m}^{-\mathbf{2}}$ & $\mathbf{B O D} \mathbf{~} \mathbf{~ g} \cdot \mathbf{L}^{\mathbf{- 1}}$ & $\mathbf{C O D}, \mathbf{m g} \cdot \mathbf{L}^{-\mathbf{1}}$ & $\mathbf{T K N}, \mathbf{g}^{\cdot} \mathbf{L}^{-\mathbf{1}}$ \\
\hline 6.7 & 5.86 & 2350 & 2980 & 1.82 \\
\hline
\end{tabular}

EC - electric conductivity, BOD Biochemical oxygen demand, COD - chemical oxygen demand, TKN - Total kjeldohl nitrogen

The corrosion rate of S235JR steel measured in mm per year was calculated with the use of the below formula (1), measured in $\mathrm{g} \cdot \mathrm{m}^{-2}$ was calculated with the use the below formula (2):

$$
\begin{aligned}
& r_{\text {corm }}=\frac{8760 \cdot \mathrm{m}}{\mathrm{s} \cdot \mathrm{t} \cdot \rho}, \\
& \mathrm{r}_{\text {corg }}=\frac{10000 \cdot \mathrm{m}}{\mathrm{s} \cdot \mathrm{t}},
\end{aligned}
$$

where $t$ - time of treatment in a corrosive solution of boiling nitric acid, hours;

$S$ - surface area of the sample, $\mathrm{cm}^{2}$;

$m$ - average mass loss in boiling solution, $\mathrm{g}$;

$\rho$ - sample density, $\mathrm{g} \cdot \mathrm{cm}^{-3}$.

The influence of animal slurry on the S235JRC carbon steel corrosion resistance was investigated using the weight loss. The mass of samples was measured by the Kern ALT 3104AM general laboratory precision balance with accuracy of measurement $0.0001 \mathrm{~g}$. The time range of the research was: 48, 96, $144,192,240,288,336,384$ and 432 hours.

Profile roughness parameters were analyzed by the Diavite DH5 profilometer, for which the maximum length of the measuring section is $15 \mathrm{~mm}$. The roughness profile of the steel consists of three periods. The first, in which the increase in the corrosion rate and surface roughness is low. The second, where there is a faster increase in roughness and the corrosion speed. The third, in which the roughness and corrosion speed are stabilized [37-38]. To emphasize all three corrosion periods, the results are presented in the form of fourth order polynomials. In order to relate the corrosion results to the proportional function, line graphs were also plotted. 


\section{Results and discussion}

Profile roughness parameters of S235JRC steel after corrosion tests in animal slurry at room temperature for 336 hours is presented in Fig. 1 and for 432 hours in Fig. 2.

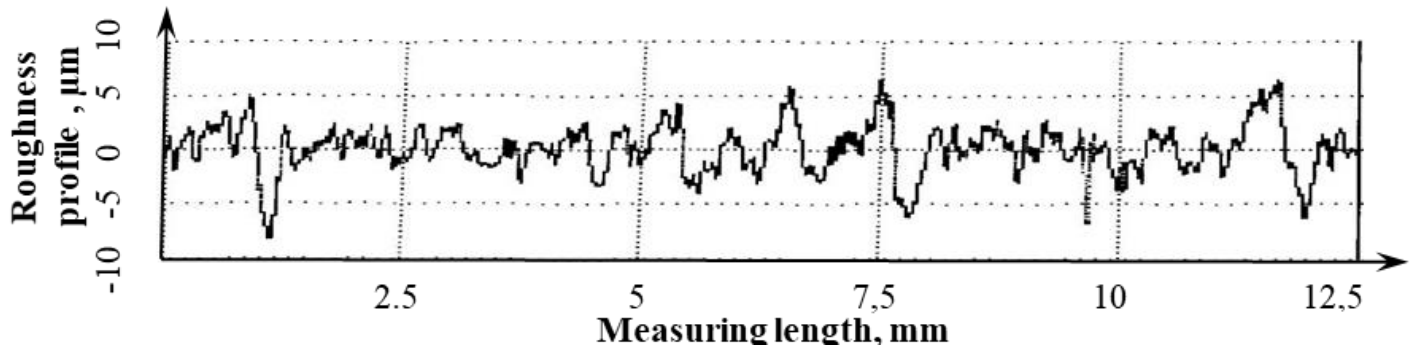

Fig. 1. Profile roughness of S235JRC steel after corrosion tests in animal slurry at room temperature for 336 hours

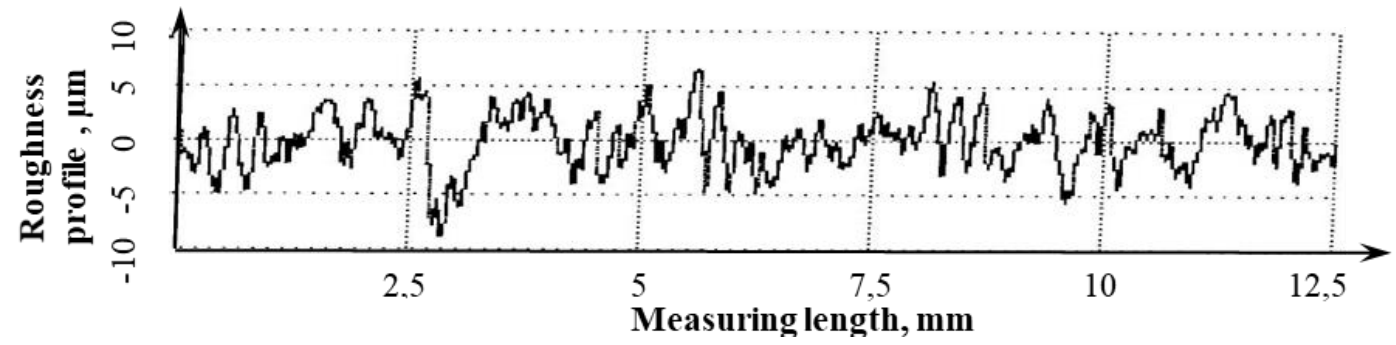

Fig. 2. Profile roughness of S235JRC steel after corrosion tests in animal slurry at room temperature for $\mathbf{4 3 2}$ hours

After the samples were kept in the corrosive medium for 336 hours, the formation of peaks of a size similar to those obtained for 432 hours of soaking time was observed. It follows that for a soaking time of about 336 hours maximum depressions are formed, and with further time increase, the peaks thicken. This density indicates an increase in the number of places where animal slurry is corrosive. Profile roughness parameters of S235JRC carbon steel for different corrosion time with the determination coefficient is presented in Fig. 3 for $R_{a}$ and $R_{q}$ and in Fig. 4 for $R_{t}$ and $R_{p}$. Changes to all profiles of roughness of S235JRC steel after corrosion tests in animal slurry at room temperature for different corrosion time can be represented with sufficient accuracy by a linear function (Fig. 3-4).

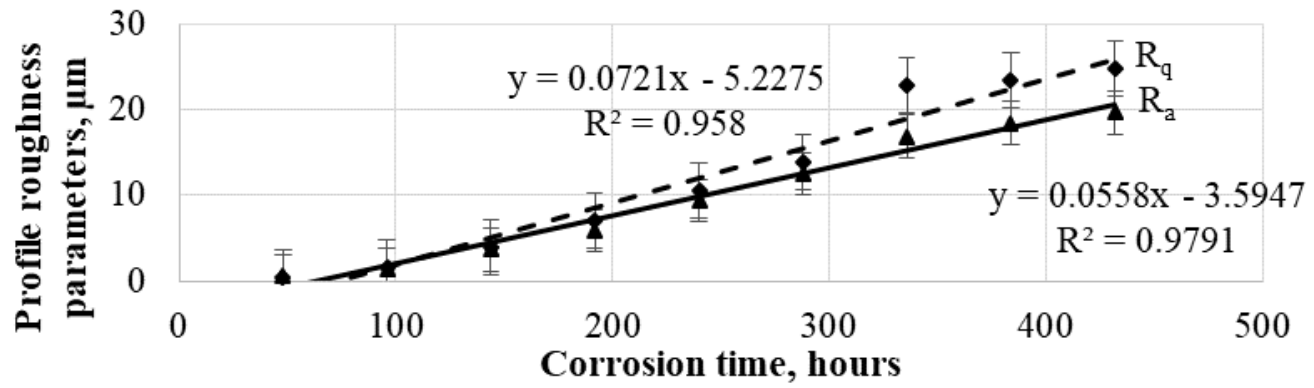

Fig. 3. Profile roughness of S235JRC steel after corrosion tests in animal slurry at room temperature for different corrosion time: $R a$ - arithmetical mean roughness value $(\mu \mathrm{m}) ; R q$ - mean peak width $(\mu \mathrm{m})$

Percentage effects of corrosion time on the relative mass loss (RML) of S235JRC carbon steel after corrosion tests in animal slurry at room temperature (Fig. 5) is sufficiently accurately described by a second degree polynomial function. Up to about 190 hours of keeping the steel in the aqueous solution or animal slurry, a slow increase in the mass corrosion loss was noted. After exceeding this time, the weight loss was faster and faster. This relationship is confirmed by the change of the $\mathrm{R}_{\mathrm{a}}$ parameter (Fig. 3). Similar observations were made for the corrosion rate with a soaking time of 288 hours. After extending the soaking time, a slow decrease in the corrosion rate was observed (Figs 6 and 7). Initially, low steel consumption is attributed to the surface hardening of the material and a lower development of 
the tested surface, while the subsequent decrease in the corrosion rate by the process tendency to stabilize.

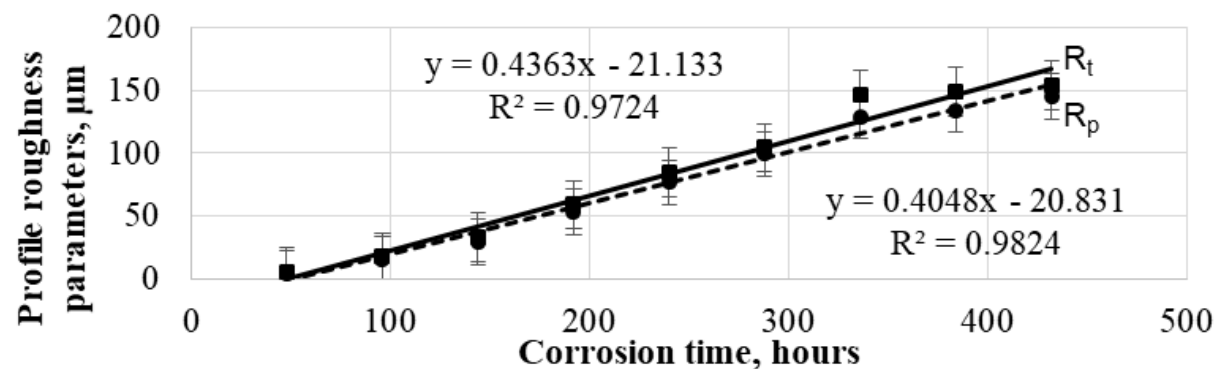

Fig. 4. Profile roughness of $\mathbf{S 2 3 5 J R C}$ steel after corrosion tests in animal slurry at room temperature for different corrosion time: $R p$ - maximum roughness depth $(\mu \mathrm{m}) ; R t$-total height of the roughness profile $(\mu \mathrm{m})$

The result of time influence of soaking the S235JRC carbon structural steel in animal slurry at room temperature on the relative mass loss $(R M L)$ with the determination coefficient is presented in Fig. 5.

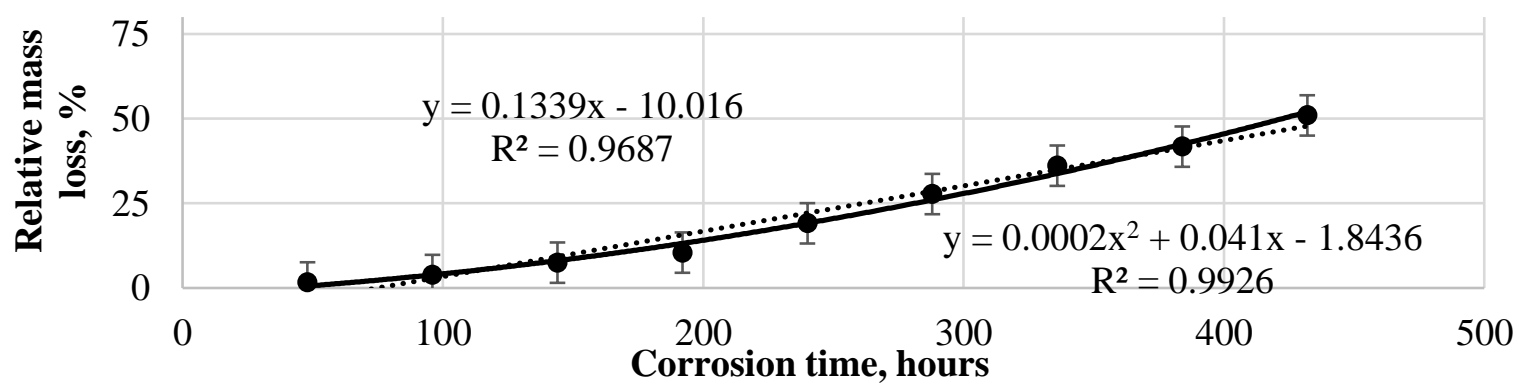

Fig. 5. Percentage effects of corrosion time on the relative mass loss (RML) of S235JRC carbon steel after corrosion tests in animal slurry at room temperature

The effect of corrosion time on the corrosion rate measured in mm per year of S235JRC steel after corrosion tests in animal slurry at room temperature with the determination coefficient is presented in Fig. 6 and in gram per $\mathrm{m}^{2}$ in Fig. 7.

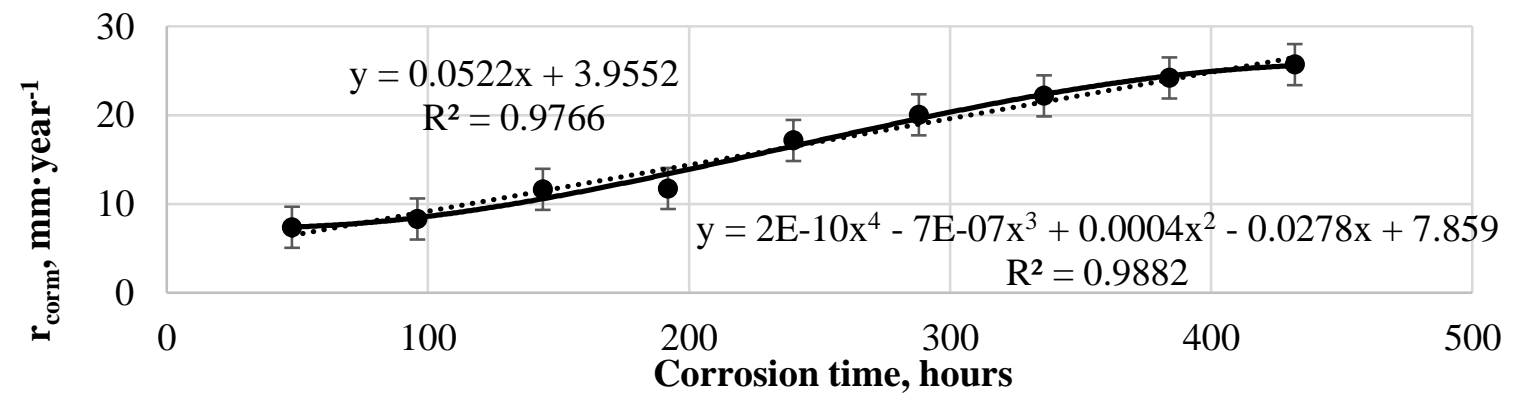

Fig. 6. Effect of corrosion time on the corrosion rate measured in mm per year of S235JRC steel after corrosion tests in animal slurry at room temperature

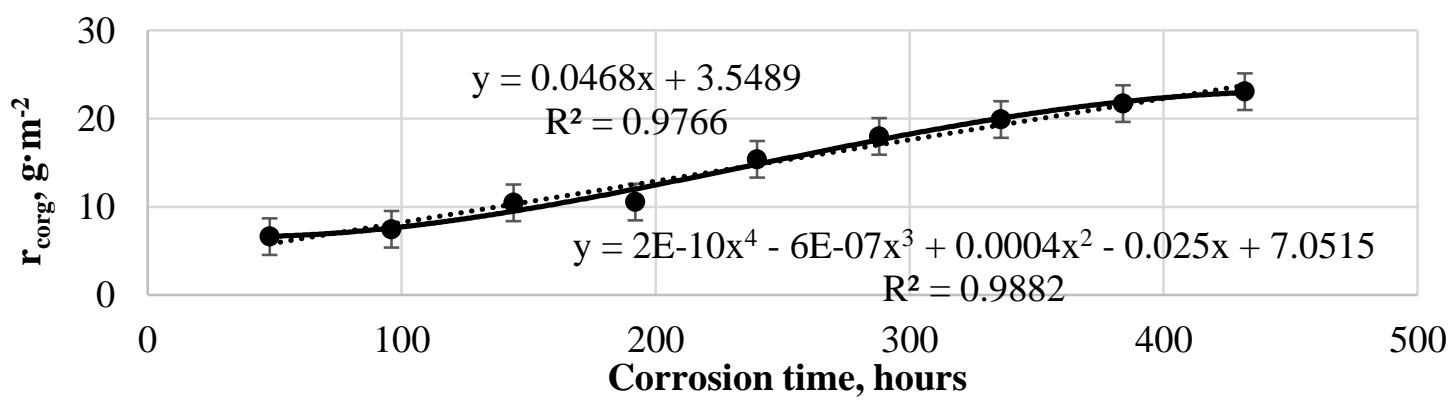

Fig. 7. Effect of corrosion time on the corrosion rate measured in gram per $\mathbf{m}^{2}$ of S235JRC steel after corrosion tests in animal slurry at room temperature 
Based on the analysis of changes in the parameters of surface roughness (Fig. 3 and Fig. 4) and corrosion rate (Fig. 6 and Fig. 7), smooth transitions between the individual stages of corrosion were found. The first period ends after 96 hours of soaking the steel, and the second period after 336 hours. Based on the results of the tests presented in this paper, as well as the results of the tests presented in [39-40], it was found that animal slurry at room temperature is an aggressive corrosive medium for steel from the S235 group, and the progress and rate of corrosion of the steel surface subjected to cold rolling are slower.

\section{Conclusions}

1. It was found that animal slurry with a room temperature is an aggressive corrosive medium for steel grades S235JRC.

2. A gentle transition between the various stages of corrosion was noted, which is reflected in the surface roughness and corrosion velocity.

\section{References}

[1] Ulewicz R., Mazur M., Bokůvka O. Structure and mechanical properties of fine-grained steels. Periodica Polytechnica Transportation Engineering 41/2, 2013, pp. 111-115.

[2] Vicen M., Bronček J., Nový F. Investigation of tribological properties of CarbonX coating deposited on 100Cr6 steel, Production Engineering Archives, 25(25), 2019, pp. 52-55.

[3] Bricín D., Křriž A. Influence of the Boriding Process on the Properties and the Structure of the Steel S265 and the Steel X6CrNiTi18-10. Manufacturing Technology 21(1), 2021, pp. 37-44.

[4] Selejdak J., Urbański M., Winiarski M. Assessment of a steel bridge corrosion degree. Proceedings of International Conference Sustainable Development: Architecture - Building Construction Environmental Engineering and Protection Innovative Energy-Efficient Technologies - Utilization of Renewable Energy Sources (SOLINA 2018), 19-23 June, 2018 Rzeszów - Polańczyk, Poland, E3S Web of Conferences Vol. 49, 00098.

[5] Nová I., Machuta J. Monitoring of the diffusion processes during carburizing automotive steel parts. Manufacturing Technology, 16(1), 2016, pp. 225-230.

[6] Korzekwa, J., Skoneczny, W., Dercz, G., Bara, M. Wear mechanism of Al2O3/WS2 with PEEK/BG plastic. Journal of Tribology, 136(1), 2014, art. 011601.

[7] Scendo, M., Trela, J., Radek, N. Influence of laser power on the corrosive resistance of WC-Cu coating. Surface and Coatings Technology, 259, 2014, pp. 401-407.

[8] Gadek-Moszczak, A. History of stereology. Image Analysis and Stereology, 36(3), 2017, pp. 151152.

[9] Hren I., Kusmierczak S., Kurajdová K., Luňák M. Analysis of the influence of surface condition on the corrosion behavior of alloy 2024. Manufacturing Technology 20(5), 2020, pp.603-611.

[10] Ulewicz R., Nový F., Quality management systems in special processes. Transportation Research Procedia 40, 2019, pp. 113-118.

[11] Dudek A., Lisiecka B., Ulewicz R., The effect of alloying method on the structure and properties of sintered stainless steel. Archives Metallurgy and Materials, vol. 62, no. 1, 2017, pp. 281-287.

[12] Pietraszek J., Gądek-Moszczak A. The smooth bootstrap approach to the distribution of a shape in the ferritic stainless steel AISI 434L Powders, Solid State Phenomena, Vol. 197, 2012, pp. 162167.

[13] Lipiński T. Corrosion effect of $20 \% \mathrm{NaCl}$ solution on basic carbon structural S235JR steel. 15th International Scientific Conference Engineering for Rural Development, Jelgava, 24-26.05.2017. Proceedings, vol. 15, pp. 1069-1074.

[14] Selejdak J., Khmil R., Blikharskyy Z. The influence of simultaneous action of the aggressive environment and loading on strength of RC beams. 12th International Conference Quality Production Improvement, Zaborze, Poland 18-20 June 2018, MATEC Web of Conferences Vol. 183, 02002/2018, $6 \mathrm{~s}$.

[15] De Belie N., Sonck B., Braam C.R., Lenehand J.J., Svennerstedte B., Richardson M. Durability of building materials and components in the agricultural environment, Part II: metal structures. J. Agric. Eng. Res., 75, 2000, pp. 333-347. 
[16] Dudek A., Wrońska A., Adamczyk L. Surface remelting of 316L + 434L sintered steel: microstructure and corrosion resistance. Journal Solid State Electronics, 18(11), 2014, pp. $2973-$ 2981.

[17] Szabracki P., Lipiński T. Influence of sigma phase precipitation on the intergranular corrosion resistance of X2CrNiMoN25-7-4 super duplex stainless steel. 23rd International Conference on Metallurgy and Materials METAL 2014, pp. 476-481.

[18] Szabracki P., Lipiński T. Effect of aging on the microstructure and the intergranular corrosion resistance of X2CrNiMoN25-7-4 duplex stainless steel. Solid State Phenomena, 203-204, 2013, pp. $59-62$.

[19]Zatkalíková, V., Markovičová, L. Influence of temperature on corrosion resistance of austenitic stainless steel in $\mathrm{Cl}-$ containing solutions. Production Engineering Archives, 25, 2019, pp. 43-46.

[20] Uhlig H.H., Revie R.W. Corrosion and corrosion control. 3rd Edition, John Wiley and Sons 1985.

[21]Kusmič D., Faltejsek P. Corrosion resistance of low temperature plasma nitrided X12CrMoWVNbN10-1-1 martensitic stainless steel. Manufacturing Technology, 19(4), 2019, pp. 619-623.

[22] Lipiński T. Corrosion resistance of 1.4362 steel in boiling $65 \%$ nitric acid. Manufacturing Technology, 16 (5), 2016, pp. 1004-1009.

[23] Lipiński T. Corrosion rate of the X2CrNiMoN22-5-3 duplex stainless steel annealed at 500 degrees C. Acta Physica Polonica A ,130 (4), 2016, pp. 993-995.

[24] Gądek-Moszczak A., Pietraszek J., Jasiewicz B., Sikorska S., Wojnar L. The bootstrap approach to the comparison of two methods applied to the evaluation of the growth index in the analysis of the digital X-ray image of a bone regenerate. Studies in Computational Intelligence, 572, 2015, pp. 127136.

[25] Scendo M., Trela J., Radek N. Influence of laser power on the corrosive resistance of WC-Cu coating. Surface and Coatings Technology, 259, 2014, pp. 401-407.

[26] Duryahina Z.A., Makhorkin I.M., Lazko H.V., Bychyns'kyi V.I. Evaluation of temperature fields in corrosion-resistant steels under the action of laser radiation. Materials Science, 43(6), 2007, pp. 800-806.

[27] Mária Blatnická, Miroslav Blatnický, Ján Dižo, Milan Sága. Comparison of analytical stress analysis and numerical calculation of mobile work machine part. Manufacturing Technology 18(2), 2018, pp. 190-193.

[28] Lipinski T., Wach A. Effect of impurities on bending fatigue strength of structural steel. 14th International Scientific Conference Engineering for Rural Development, Jelgava, 20-22.05.2015. Proceedings, vol. 14, pp. 784-789.

[29] Dvorský D., Kubásek J., Vojtěch D. Microstructure, mechanical and corrosion properties of extruded milled magnesium powder. Manufacturing Technology 20(6), 2020, pp. 708-713.

[30] Selejdak J. Influencing factors onto quality of welded pipes. Metalurgija, 42 (1), 2003, pp. 65-67.

[31] Yu B., Li D.Y. Grondin Ame'lie. Effects of the dissolved oxygen and slurry velocity on erosioncorrosion of carbon steel in aqueous slurries with carbon dioxide and silica sand. Wear, 302, 2013, pp. 1609-1614.

[32] Tang X., Xu L.Y., Cheng Y.F. Electrochemical corrosion behavior of X-65 steel in the simulated oil-sand slurry. Synergism of erosion and corrosion. Corrosion Science, 50, 2008, pp. 1469-1474.

[33] Lu B.T., Lu J.F., Luo J.L. Erosion-corrosion of carbon steel in simulated tailing slurries. Corrosion Science, 53, 2011, pp. 1000-1008.

[34] Aguirre J., Walczak M. Effect of dissolved copper ions on erosion-corrosion synergy of X65 steel in simulated copper tailing slurry. Tribology International, 114, 2017, pp. 329-336.

[35] Yang Y., Cheng Y.F. Parametric effects on the erosion-corrosion rate and mechanism of carbon steel pipes in oil sands slurry. Wear 276-277, 2012, pp. 141-148.

[36] Song F. G., Du L.G. Erosion corrosion of low-alloy wear-resistant steels in alkaline slurry. Journal of Ironand Steel Research, International 24, 2017, pp. 1065-1072.

[37] Lipiński T. Corrosion Effect of Animal Slurry on Low Carbon S235JR Steel at 333 K. Proceedings of the 8th International Scientific Conference Rural Development 2017, Lithuania 23-24 November, pp. 352-358. 
[38] Lipiński T., Karpisz D. Effect of animal slurry on carbon structural S235JR steel at 303 K. 19th International Scientific Conference Engineering for Rural Development, Jelgava, 20-22.05.2020. Proceedings, vol. 19, pp. 1482-1487.

[39] EN 10277-2 : 2008, Bright steel products - technical delivery conditions - part 2

[40] PN EN ISO 3651-1, Determination of resistance to intergranular corrosion of stainless steels. 